\title{
A life cycle stakeholder management framework for enhanced collaboration between stakeholders with competing interests
}

\section{Christina Scandelius and Geraldine Cohen,}

\section{Brunel Business School, Uxbridge, UK}

\begin{abstract}
Implementation of a Life Cycle Sustainability Management (LCSM) strategy can involve significant challenges because of competing or conflicting objectives between stakeholders. These differences may, if not identified and managed, hinder successful adoption of sustainability initiatives. This article proposes a conceptual framework for stakeholder management in a LCSM context. The framework identifies the key sustainability stakeholder groups and suggests strategic ambiguity as a management tool to harness dysfunctional conflict into constructive collaboration. The framework is of practical value as it can be used as a guideline by managers who wish to improve collaboration with stakeholders along the supply chain. The article also fills a gap in the academic literature where there is only limited research on sustainability stakeholder management through strategic ambiguity.
\end{abstract}




\section{Introduction}

Implementation of a Life Cycle Sustainability Management (LCSM) strategy can involve significant challenges because of competing or conflicting objectives between stakeholders. These differences may, if not identified and managed, hinder successful adoption of sustainability initiatives, which may not only harm a business's performance [1], but may also delay development to more sustainable production and consumption practices. Based on the definitions for Life Cycle Management [2] and Sustainable development [3], we suggest the following definition for Life Cycle Sustainability Management (LCSM): A strategic management system which aims at minimizing an organisation's negative impact on the natural and social environment by its products or services along the entire product/service life cycle and value chain, to warrant that natural, social and economical resources are sustained for future generations.

This definition calls for close collaboration between stakeholders along the value chain, and also interaction with stakeholders who represent the natural and social environment. Organisations will need to form relationships with a wide range of different stakeholders, and if the optimal route towards sustainable production and consumption is unclear, these relationships might be jeopardised by conflicting ideas on how to best use resources.

In the next sections we will critically review the academic literature on sustainability stakeholders, sources for tension between these stakeholders, and strategic ambiguity as a suggested tool to manage diverse stakeholders. A case study will explore how ambiguous communication could be used in a LCSM context. Finally, we will present a conceptual framework suggesting how to reduce tension between sustainability stakeholders and encourage collaboration. 


\section{Identification of sustainability stakeholders}

The previous section introduced us to LCSM and the importance of collaboration between stakeholders to ensure sustainable development of products and services along the whole life cycle and value chain. It is therefore vital for a business to understand which stakeholder groups that have legitimacy, urgency and power [4] to collaborate in a LCSM context. A range of scholars have, based on Freeman's stakeholder theory [5], attempted to identify 'green stakeholders'. Early examples include Henriques and Sadorsky [6, 7] with their four groups of environmental or green stakeholders: regulators, organisational (including customers, suppliers, employees and shareholders), media and local communities. Fineman and Clarke [8] choose to rather name the green stakeholder groups as planet, regulatory, stakeholders with indirect interests, and internal stakeholders. In essence these groups of stakeholders are the same as the ones introduced by Henriques and Sadorsky [6, 7], but they have chosen to categorize them differently and use slightly different names. For example, they [8] introduce 'planet' as a separate stakeholder, represented by environmental pressure groups and they also suggest the term 'stakeholders with indirect interest' to classify those stakeholders that consider environmental progress as a secondary benefit, and whose priorities are other aspects. This group includes a wide range of heterogeneous stakeholders like shareholders, customers and media. Harvey and Schaefer [9] refer to the green stakeholders as suggested by Fineman and Clarke [8] but found evidence that this classification is rather academic as many companies do not take a systematic approach to categorise and manage green stakeholders. A more recent attempt to identify green stakeholders was conducted by Rivera-Camino [10] who suggests that there are four major green stakeholder groups: market (including customers, distributors and suppliers), social stakeholders (e.g. local communities), immediate providers (shareholders, labour unions etc) and legal stakeholders. 
This section has identified the key green stakeholder groups. To better reflect the definition of LCSM, also the social aspect of sustainability should be considered and addressed more clearly, and a more appropriate term would be sustainability stakeholders. The next section will address sources for competing interests between and within these groups.

\section{Sources for tension between stakeholders}

The sheer number of sustainability stakeholders, as identified in the previous section, indicates that tension or even conflict is likely to arise as an effect of sustainability initiatives or lack of initiatives, or as phrased by Reynolds et al [11]: "Whether the resources are capital, profits, effort, or time, stakeholders can and do disagree about how or where each should be utilized".

In addition, there are also some sources to tension specifically applicable to sustainability initiatives. Firstly, several unclear definitions of sustainability exist $[12,13]$ which may lead to different perspectives on the best cause of action, both internally between departments in an organisation, as well as between different organisations [14]. In addition, despite many efforts by academics and practitioners to develop processes to assess a product's impact on the social and natural environment along its life span, there is still no conclusive method available [15]. Another source to tension could be the lack of sufficient evidence that sustainability initiatives are beneficial for all stakeholders of a business [16], which may lead to resistance from certain stakeholder groups. These factors indicate that the various sustainability stakeholders are likely to have conflicting ideas on what actions need to be taken in order to achieve progress towards sustainability. 


\section{Strategic ambiguity as a tool to manage stakeholders}

The previous section introduced us to the complex and diverse stakeholder situation that characterises LCSM. How can a business harness the possible conflicting demands and encourage constructive collaboration between the stakeholders? Davenport and Leitch [17] suggest that while clarity is important in communication when the goal is clear, they argue that “.......when the goal is less clear, when stakeholders are not compliant and, perhaps, have power bases from which to resist the goal, or when achievement of the goal requires a creative engagement between the organization and its stakeholders, strategic ambiguity may be more appropriate".

One of the pioneers to introduce strategic ambiguity into the business communication literature was Eisenberg, in his seminal article of 1984 [18]. He argues that while clarity is an important aspect of communications, it might be more pragmatic to refrain from being too specific in situations where multiple contradicting goals exist. He proposes strategic ambiguity, the intentional use of ambiguous messages, as a management tool for businesses to achieve endorsement from their stakeholders. This is also supported by more recent research; for example Davenport and Leitch [16] define strategic ambiguity as:

“...the deliberate use of ambiguity in strategic communication in order to create a 'space' in which multiple interpretations by stakeholders are enabled and to which multiple stakeholder responses are possible".

Eisenberg's conceptual theories [18], have been empirically tested in contexts of 
organisational change in the public sector $[17,19,20]$, in crisis communication in a fast food chain [1], and in the context of social marketing in a non-profit organisation [21]. Sustainability is mentioned in relation to strategic ambiguity in the context of policy documentation [12], where 'sustainability' and 'growth' were used as ambiguous keywords to facilitate collaboration between stakeholders of conflicting ideological beliefs. In addition Wexler [22] presents a conceptual model suggesting that strategic ambiguity can be beneficial to encourage collaboration between three stakeholder groups (people, profit and planet), around the ambiguous concept of the 'Triple Bottom Line' (TBL). Wexler's work is however reducing stakeholders into these three vaguely defined groups and is limited to one reporting tool of sustainability, the Triple Bottom Line (TBL), and he calls for further research into the applicability of strategic ambiguity beyond an intra-organizational context.

The literature review above indicates that strategic ambiguity can be beneficial to reduce tension and encourage collaboration with stakeholders in contexts characterised by diverse stakeholders and unclear goals. These contexts share similarities to circumstances around implementation of a LCSM strategy, and lead us to believe that strategic ambiguity might be a useful tool in managing sustainability stakeholders. The next section will therefore exemplify how strategic ambiguity can be used to communicate with sustainability stakeholders through a case study. 


\section{Case study on strategic ambiguity to manage sustainability stakeholders around coffee brands}

This section will illustrate how strategic ambiguity can be used in practice in LCSM, by studying examples of ambiguous sustainability communications to stakeholders around a coffee brand, with a specific focus on packaging. It should be noted that the research is still ongoing and that the section below will present some initial observations.

\subsection{Background and methodology}

The chosen case study relates to Kraft Foods, and more specifically their coffee brand Kenco. Coffee brands are interesting from a sustainability perspective as the coffee value chain can have a significant impact on the social and natural environment, through its origin in regions characterised by economical poverty, and its significant water and energy consumption. Kenco coffee is of particular interest as it is positioned as a sustainability brand, and is projecting its sustainability ethos on its packaging design. Packaging can in itself become a source for stakeholder conflict through the multifaceted functions that it needs to fulfil. It needs to ensure sufficient protection and preservation of the goods the packaging is intended for, and decisions on packaging design will not only have an impact on sustainability for the packaging itself but will determine transportation efficiency and waste reduction also for the product it protects [23]. It is therefore paramount to adopt a holistic approach with close collaboration with stakeholders along the supply chain to ensure minimum adverse environmental impact along the life cycle of both product and packaging. In addition packaging serves as a promotional platform as it is an important tool to attract consumers and to support brand image [24]. Last but not least, because packaging has become a very visible symbol for waste, there is significant pressure for sustainability efforts from various external stakeholder groups. Managing stakeholders around a coffee brand is thus likely to be 
challenging, balancing very diverse stakeholders, requiring collaboration to achieve improved conditions. Therefore sustainability communications around a coffee brand should pose a very interesting context for research into strategic ambiguity.

The results presented below are initial observations from ongoing exploratory research, applying case study design to explore the concept of strategic ambiguity in the management of stakeholders around the food and beverage industry. As there is very limited research available on strategic ambiguity in LCSM, a case study design is used combining qualitative methods such as interviews and documentary data collection to explore formal internal and external communication in depth [25]. Qualitative interviews are chosen as a suitable method in this case study design, as it provides more flexibility to follow up on new insights in areas that is not well known and it also provides more detailed answers compared to quantitative research [26]. The findings presented below are based on two in-depth semi-structured interviews, each lasting up to 2 hours, with directors of The British Packaging Federation. The interviewees were selected following their long experience (more than 30 years) in supplying packaging to the food and beverage industry, having held positions within manufacturing management and as CEOs. In addition, secondary data was collected from publicly available reports, web sites, newspapers and journal articles.

\subsection{Discussion on ambiguous sustainability communications around a coffee brand}

Kenco (part of Kraft Foods) is positioned as a sustainable coffee brand, announcing their social and environmental responsibility through sourcing coffee beans only from rainforest alliance certified farms, and taking initiatives to reduce packaging waste. Communications on 
their website and on TV ads, targeted towards consumers and natural environment stakeholders are primarily focused around their 'eco-refill' packaging which is claimed to reduce $97 \%$ waste compared to the traditional glass jars [27]. From a weight perspective they have reduced waste, however the eco-refill pouch is not easily recyclable and can currently not be recycled by local authorities in the UK. Instead they encourage consumers to take action to recycle by sending empty eco-refill pouches to TerraCycle, an organisation who will convert the empty bags into products like umbrellas and notebooks. The shift to the eco-refill bag is significant from a promotional aspect. In an industry where the majority of instant coffee brands are sold in glass jars, the eco-refill bag stands out on the shop shelf. Kenco has here been able to cleverly meet demands from a promotional aspect, i e packaging that gains attention, and also supports the sustainability image of Kenco, as the refill pouch signifies waste reduction through its size compared to the glass jars. While Kenco promote their achievements of reducing waste, other aspects of sustainability challenges, like energy and water consumption along the coffee value chain are played down or left out. This stance is interesting as one of their competitors, Nescafe (part of Nestle) take a different focus in sustainability communications. While Nescafe also offer coffee in pouches, the majority is sold in glass jars and they highlight the advantage of using glass as a natural material that is easy to recycle [28].

In communications to economic stakeholders (e.g. investors), the angle is different and sustainability is mentioned in connection with economical growth:

"To build and sustain brands people love and trust, one must focus-not only on today but also on tomorrow. It's not easy...but balancing the short and long term is key to delivering sustainable, profitable growth-growth that is good for our shareholders but also good for our 
consumers, our employees, our business partners, the communities where we live and work, and the planet we inhabit" [29].

The interviews [30,31] reveal that sustainability communications from the major consumer brands to the packaging suppliers are focusing on keywords as 'cost efficiency', using less material and/or less energy to achieve cost savings which also has a secondary benefit from an environmental perspective. Environmental initiatives, in the form of reduced packaging or more environmentally friendly processes, are considered very attractive and seen as added value and might secure a supply position, however these initiatives are expected to be sponsored by the packaging suppliers. Cost and quality dimensions will often take precedence over sustainability. It was mentioned that one underlying cause for sustainability related tension in the value chain is the often uneducated debate on waste, where the packaging industry is blamed because of the visibility of packaging [30, 31]. It was highlighted that statistics suggest that as much as $30 \%$ of food is wasted in the UK, and that some of this could be reduced by more clever packaging solutions [30]. It might however pose as less attractive for some members in the value chain to address the waste problem, as less waste means less consumption and less revenue. Or, as expressed by one of the interviewees [31]:

"The industry, at the moment, is dominated by 'greenwash', and I mean again, if you stand back, one of the biggest fundamental issues we have is that most people don't begin to understand what packaging is and what it does".

He further points out that:

"Rather than educate the public, the retailers will say: We are doing the right thing - we are 
reducing the packaging" [31].

Therefore, in the absence of regulations controlling food waste, the big consumer brands and retailers will continue to push their suppliers for primarily cost reducing solutions"[30, 31].

The initial observations from this case study indicate existence of competing interests in the value chain around balancing cost, quality, revenue and sustainability initiatives. The findings further suggest that strategic ambiguity is practised in sustainability communications, applying keywords of different meanings depending on the stakeholders being targeted. Further research is suggested to explore the objectives behind the choice of keywords and decisions to play down certain aspects, and also to better understand how the message is interpreted by the various stakeholder groups [18] and how it may encourage them to collaboration.

\section{Presentation of a conceptual framework to manage sustainability stakeholders in a LCSM context}

The previous sections have identified the key sustainability stakeholder groups, highlighting sources for conflict between these groups, and suggested strategic ambiguity as a tool to manage diverse stakeholders. Based on this, and the findings from the case study we propose a conceptual framework for managing sustainability stakeholders in a LCSM context (fig. 1). This framework builds on the green stakeholder models suggested by Henriques and Sadorsky [7], Fineman and Clarke [8] and Rivera-Camino [10], however as LCSM is considering the natural and social environment as two equally important constructs, this will be reflected by classifying them as two distinct groups, and by using the term 'sustainability 
stakeholders'. The framework identifies five key sustainability stakeholder groups: Economic stakeholders, Social stakeholders, Natural environment stakeholders, Value chain stakeholders and Internal stakeholders. The Natural environment is represented by green pressure groups, regulators and legislators who pursue a green agenda, the public, media etc. The social stakeholder group is represented by social pressure groups that may or may not be the same as for natural environment, regulators and legislators from a social perspective, media and the public. In addition, as opposed to Rivera-Camino's [10] suggestion to include labour unions in 'immediate providers', the framework here suggests that labour unions belong to the social stakeholder group, as their function is to ensure its members welfare. The economic stakeholders are those who have an economic interest in the business, for example shareholders, financial institutions etc. Additionally, we add internal stakeholders to the model, as suggested by Fineman and Clarke [8]. The market stakeholders in Rivera-Camino's model [10] are here named as 'value chain stakeholders' to better reflect the participants in this group, which are customers, suppliers, distributors, etc. 


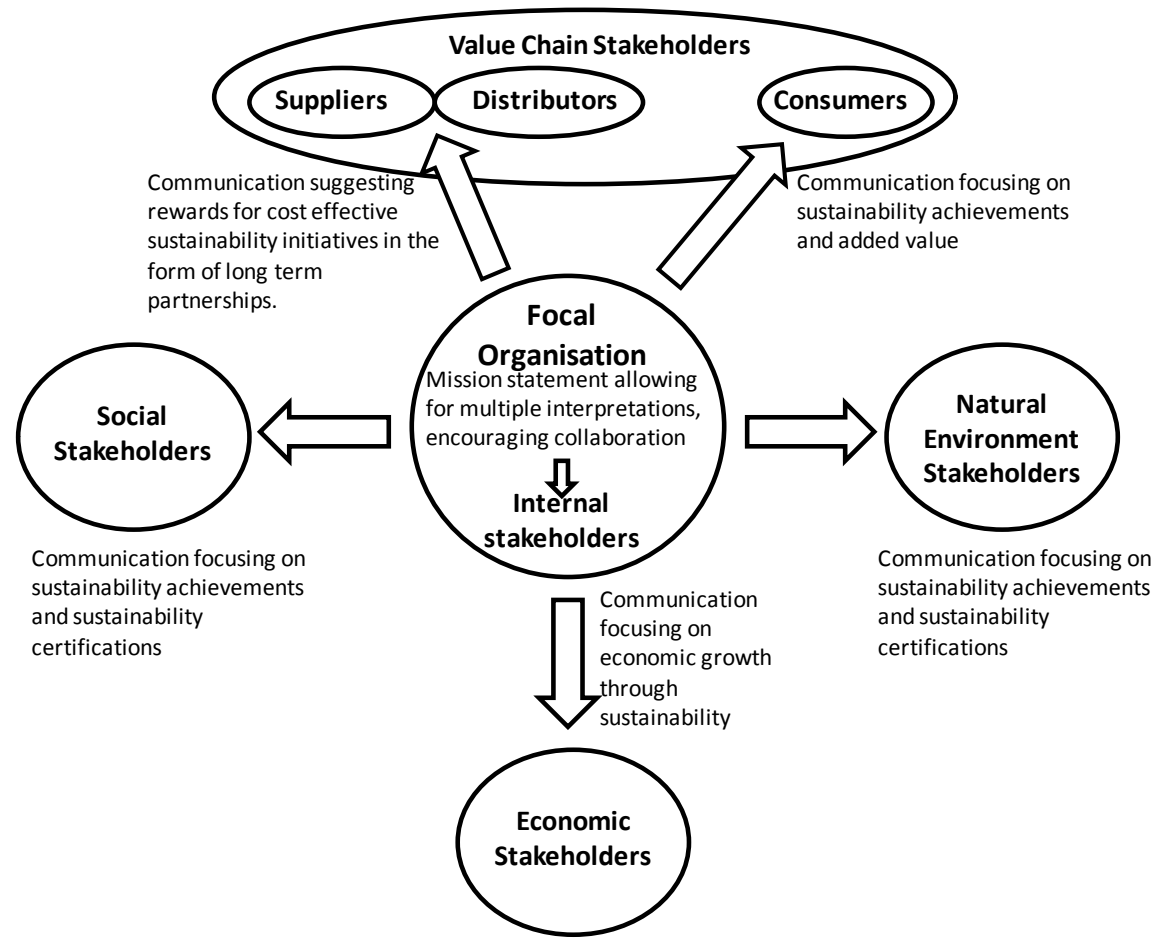

Fig.1: Framework for sustainability stakeholder management in a LCSM context

The framework illustrates how an organisation can categorize its stakeholders according to the nature of their interests, and adapt the sustainability communications accordingly. The message may contain mission statements, keywords or metaphors that allows for multiple interpretations $[12,18,19]$, it may leave out or play down certain aspects to create common ground [21] or to avoid confusion or indecision [17, 20]. The case study also reveals that different keywords may be used to different stakeholder groups, with the purpose of stimulating a positive response to collaboration.

While many scholars suggest prioritisation of stakeholders $[6,7]$, we suggest to rather consider them all as equally important as the power may change over time, and for a long term perspective it is therefore important to avoid giving some groups precedence over others $[4,32,33]$. 


\section{Conclusions}

This conceptual paper has highlighted stakeholder related challenges facing organisations implementing a LCSM strategy. The most relevant stakeholders, named sustainability stakeholders, were identified and the sources for possible tension were explained. A literature review on strategic ambiguity presented evidence on its usefulness to reduce tension and encourage collaboration in contexts characterised by diverse stakeholders and/or goals. The applicability of strategic ambiguity in a LCSM context was illustrated by a case study, giving examples of ambiguous sustainability communications around a coffee brand. Finally a conceptual framework for stakeholder management in a LCSM context was presented. The framework is of practical value as it can be used as a guideline by managers who wish to improve collaboration with stakeholders along the supply chain to optimise sustainability efforts. The article also fills a gap in the academic literature where there is only limited research on stakeholder management and strategic ambiguity in a sustainability context. Further empirical research is however suggested, to verify the validity of the proposed framework.

\section{References}

[1] Ulmer, R.R. and Sellnow, T.L., Consistent Question of Ambiguity in Organizational Crisis communication: Jack in the Box as a Case Study, Journal of Business Ethics, Vol. 25, 2000, pp. 143-155

[2] UNEP (United Nations Environmental Programme), 2007. Life Cycle Management - A 
Business Guide to Sustainability. 〈http://www.lcinitiative.unep.fr>, (Accessed 15.05.2009).

[3] WCED (World Commission on Environment and Development), Our Common Future, Oxford: Oxford University Press 1987

[4] Mitchell, R., Agle, B. and Wood, D., Toward a theory of stakeholder identification and salience: defining the principle of who and what really counts, Academy of Management Review, Vol. 22 No. 4, 1997, pp. 853-86.

[5] Freeman, E.R., Strategic Management: A Stakeholder Approach, Pitman/Ballinger, Boston, MA, 1984

[6] Henriques, I. and Sadorsky, P., The determinants of an environmentally responsive firm: an empirical approach, Journal of Environmental Economics and Management, Vol. 30 No. 3, 1996, pp. 381-95.

[7] Henriques, I. and Sadorsky, P., The relationship between environmental commitment and managerial perceptions of stakeholder importance, Academy of Management Journal, Vol. 42 No. 1, 1999, pp. 87-99.

[8] Fineman, S. and Clarke, K., Green stakeholders: industry interpretations and response, Journal of Management Studies, Vol. 33 No. 6, 1996, pp. 715-30.

[9] Harvey, B. and A. Schaefer, Managing Relationships with Environmental Stakeholders: A Study of U.K. Water and Electricity Utilities, Journal of Business Ethics, Vol. 30, 2001, pp. $243-260$.

[10] Rivera-Camino, J., Re-evaluating green marketing strategy: a stakeholder perspective, European Journal of Marketing, Vol. 41, No. 11/12, 2007, pp. 1328-1358

[11] Reynolds, S. J., Schultz, F.C., Hekman, D.R., Stakeholder Theory and Managerial DecisionMaking: Constraints and Implications of Balancing Stakeholder Interests, Journal of Business Ethics, Vol. 64, No. 3, 2006, pp.285-301

[12] Leitch, S. and Davenport, S. Strategic ambiguity as a discourse practice: the role of keywords 
in the discourse on sustainable biotechnology, Discourse Studies, Vol. 9 No. 1, 2007, pp. 4361

[13] Smith, P., Sharicz, C., The shift needed for Sustainability, Learning Organization, Vol. 18 No. 1, 2011, pp. 73-86

[14] Rex, E., Baumann, H., Individual adaptation of industry LCA practice: Results from two case studies in the Swedish forest products industry, The International Journal of Life Cycle Assessment, Vol. 12, No. 4, 2007, pp. 266-271

[15] Hunkeler, D., Rebitzer, G., The Future of Life Cycle Assessment, The International Journal of Life Cycle Assessment, Vol. 10 (5), 2005, pp. 305 - 308

[16] Spar, D.L., La Mure, L., The Power of Activism: Assessing the impact of NGOs on global business, California Management Review, Vol. 45, Issue 3, 2003, pp. 78, 24 pgs.

[17] Davenport, S. and Leitch, S., Circuits of power in practice: Strategic Ambiguity as delegation of authority, Organization Studies, Vol. 26 No. 11, 2005, pp. 1603-23

[18] Eisenberg, E.M., Ambiguity as strategy in organizational communication, Communication Monographs, Vol. 51, No. 3, 1984, pp. 227-42.

[19] Leitch, S. and Davenport, S., Strategic ambiguity in communicating public sector change, Journal of Communication Management, Vol 7, 2, 2002, pp. 129 - 139

[20] Denis, J-L., Dompierre, G., Langley, A., Rouleau, L., Escalating Indecision: Between Reification and Strategic Ambiguity, Organization Science, Vol. 22, No. 1, 2011, pp. 225244

[21] Dickinson-Delaporte, S., Beverland, M., Lindgreen, A., Building Corporate reputation with stakeholders - Exploring the role of message ambiguity for social marketers, European Journal ofMarketing, Vol. 44, No. 11-12, 2010, pp. 1856-1874

[22] Wexler, M.N., Strategic ambiguity in emergent coalitions: the triple bottom line, Corporate Communications: An International Journal, Vol. 14, No. 1, 2009, pp. $62-77$ 
[23] Hopkins, M., How Sustainability Creates New Opportunity, MIT Sloan Management Review, Vol. 51, No. 4, 2010, pp. 65-69

[24] Underwood, R., Ozanne, J., Is your packaging an effective communicator? A normative framework for increasing the communicative competence of packaging, Journal of Marketing Communications, Vol. 4, 1998, pp. 207-220

[25] Yin, R.K., Case Study Research, Design and Methods, Second Edition, Sage Publications, Newbury Park, CA. 1994

[26] Bryman, A., Bell, E., Business Research Methods, 2nd edition. Oxford: Oxford University Press. 2007

[27] <http://www.kenco.co.uk>, (Accessed 28.01.2011)

[28] <http://www.nescafe.com>, (Accessed 01.04.2011)

[29] Kraft Food Responsibility Report 2010, <http://www.kraftfoodscompany.com>, (Accessed 01.04.2011)

[30] Interviewee A, Director of the British Packaging Federation, Interviewed in London on 15.09.2010

[31] Interviewee B, Director of the British Packaging Federation, Interviewed in London on 21.09.2010

[32] Polonsky, M.J., Stakeholder management and the stakeholder matrix: potential strategic marketing tools, Journal of Market-Focused Management, Vol. 1 No. 3, 1996, pp. 209-29

[33] Polonsky, M.J., Scott, D., An empirical examination of the stakeholder strategy matrix, European Journal of Marketing, Vol. 39, No. 9/10, 2005, pp. 1199-1215 